07

\title{
Фотопроводящий THz-детектор на основе сверхрешеточной гетероструктуры с плазмонным усилением
}

\author{
() А.В. Горбатова ${ }^{1}$, Д.И. Хусяинов ${ }^{1}$, А.Э. Ячменев ${ }^{2}$, Р.А. Хабибуллин ${ }^{2}$, Д.С. Пономарев ${ }^{2}$, А.М. Буряков ${ }^{1}$, \\ Е.Д. Мишина ${ }^{1}$ \\ ${ }^{1}$ МИРЭА - Российский технологический университет, Москва, Россия \\ ${ }^{2}$ Институт сверхвысокочастотной полупроводниковой электроники им. В.Г. Мокерова РАН, Москва, Россия \\ E-mail: gorbatova.anastasiya@mail.ru
}

Поступило в Редакцию 30 июня 2020г.

В окончательной редакции 29 июля 2020 г.

Принято к публикации 29 июля 2020 г.

\begin{abstract}
Предложен высокочувствительный терагерцевый $(\mathrm{THz})$ детектор на основе фотопроводящей антенны (ФПА) с плазмонным усилением на базе сверхрешеточной гетероструктуры InGaAs/InAlAs. Экспериментально обнаружено заметное увеличение фототока, регистрируемого плазмонным ФПА-детектором, и отношения сигнал/шум по сравнению с аналогичными параметрами для ФПА-детектора без плазмонных электродов. Эффективность работы плазмонных электродов экспериментально подтверждена методом импульсной $\mathrm{THz}-$ спектроскопии посредством измерения зависимости амплитуды THz-сигнала детектора от поляризации падающего лазерного излучения накачки.
\end{abstract}

Ключевые слова: фотопроводящая антенна, терагерцевый детектор, сверхрешетка, InGaAs/InAlAs, плазмонная решетка, плазмонные электроды.

DOI: 10.21883/PJTF.2020.22.50300.18442

Фотопроводящие антенны (ФПА) относятся к наиболее распространенным источникам и приемникам широкополосного терагерцевого $(\mathrm{THz})$ излучения в системах $\mathrm{THz}$-спектроскопии и построения изображений. Однако на данный момент коммерчески доступные ФПА все еще имеют низкую эффективность оптико-THz-преобразования. Эффективность ФПА определяется как свойствами фотопроводящего слоя [1-3], так и топологией электродов [4]. Большинство коммерческих антенн изготавливается на основе GaAs или тройного соединения InGaAs [5]. В отличие от $\mathrm{GaAs}$ твердый раствор InGaAs способен эффективно работать в более широком диапазоне длин волн (до $1.5 \mu \mathrm{m}$ ). Это важно для упрощения и снижения стоимости систем генерации и детектирования THz-излучения на основе ФПА. При этом слои нелегированного InGaAs имеют очень низкое удельное сопротивление и высокие времена жизни фотовозбужденных носителей заряда, что ограничивает использование этого материала в качестве базового материала для ФПА. Для улучшения обеих характеристик применяются различные методы, среди которых выращивание пленок InGaAs при пониженной температуре с последующим компенсационным легированием [6,7], ионная имплантация $[8,9]$, легирование пленок атомами железа $[1,10]$, облучение высокоэнергетическими ионами брома [11], создание сверхрешеточных структур ErAs/InGaAs [12] с компенсацией собственной проводимости, а также использование как согласованных по параметру решетки $[13,14]$, так и упругонапряженных [15] сверхрешеточных структур InGaAs/InAlAs. За счет высокой эффективности ФПА на основе сверхрешеточных гетероструктур InGaAs/InAlAs [14] они стали широко использоваться для производства антенн. С точки зрения увеличения конверсии ФПА наиболее эффективным методом является создание метаповерхности в зазоре между электродами антенны. Такая метаповерхность может представлять собой как отдельно рассредоточенные в зазоре антенны элементы (островки, квантовые точки и др.) [16], так и наноструктурированную решеточную электродную структуру [17]. Метаповерхность обеспечивает локальное усиление электрического поля лазерного импульса вблизи границы металл/полупроводник за счет возбуждения поверхностных плазмонных волн [18]. В настоящей работе предложен дизайн THz-детектора на основе ФПА с плазмонным усилением на базе сверхрешеточной гетероструктуры InGaAs/InAlAs и исследованы его свойства. Детектор имеет высокую чувствительность в полосе пропускания до $1.5 \mathrm{THz}$.

Пленки изготовленных ФПА представляют собой сверхрешеточную (СР) гетероструктуру, состоящую из 30 периодов последовательности слоев $\operatorname{In}_{0.53} \mathrm{Ga}_{0.47} \mathrm{As}$ $(12 \mathrm{~nm}) / \mathrm{In}_{0.52} \mathrm{Al}_{0.48} \mathrm{As}(4 \mathrm{~nm})$. В качестве подложки используется пластина полуизолирующего GaAs с кристаллографической ориентацией в плоскости (100). Между СР-гетероструктурой и подложкой расположен ступенчатый буферный слой толщиной $0.65 \mu \mathrm{m}$, состоящий из пяти слоев $\mathrm{In}_{0.1-0.53} \mathrm{AlAs}$, для согласования параметров кристаллической решетки слоев $\mathrm{In}_{0.53} \mathrm{Ga}_{0.47} \mathrm{As}$, $\mathrm{In}_{0.52} \mathrm{Al}_{0.48} \mathrm{As}$ с подложкой. Всего было изготовлено три образца ФПА: 1) логарифмическая ФПА с металлизацией непосредственно на поверхности гетероструктуры; 2) ФПА с диэлектрическим слоем $\mathrm{Si}_{3} \mathrm{~N}_{4}$ толщиной 

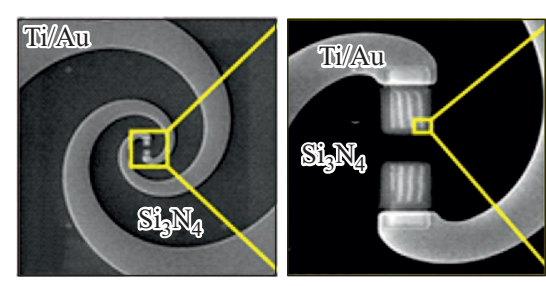

$$
\begin{aligned}
&-100 \mu \mathrm{m}-10 \mu \mathrm{m} \quad-400 \mathrm{~nm} \\
& 1-\text { Conventional PCA } \\
& 2-\text { Conventional PCA with } \mathrm{Si}_{3} \mathrm{~N}_{4} \\
& 3-\text { Plasmonic PCA with } \mathrm{Si}_{3} \mathrm{~N}_{4}
\end{aligned}
$$

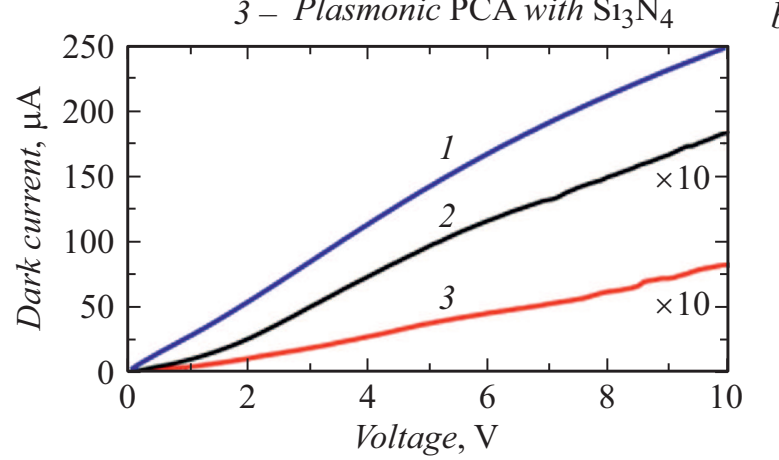

Рис. 1. $a-$ изображения ПУ-ФПА с диэлектрическим слоем $\mathrm{Si}_{3} \mathrm{~N}_{4}$, полученные с помощью электронного растрового микроскопа: общий вид (слева), увеличенное изображение области зазора антенны (в центре) и увеличенное изображение наноструктурированной решетки (справа). $b-$ темновые вольт-амперные характеристики исследуемых антенн.

$230 \mathrm{~nm}$, нанесенным на поверхность гетероструктуры (Д-ФПА); 3) ФПА с плазмонным усилением (ПУ-ФПА) с метаповерхностью на основе наноструктурированных решеток, расположенных в зазоре антенны, и диэлектрическим слоем $\mathrm{Si}_{3} \mathrm{~N}_{4}$. Технология нанесения диэлектрического слоя между фотопроводящим слоем и металлизацией ФПА уменьшает площадь контакта электродов антенны, что позволяет существенно уменьшить темновой ток в ФПА, определяющий уровень шума в ФПА-детекторе. Рисунок металлизации электродов антенн формировался методом контактной фотолитографии с последующим термическим напылением слоя металлизации $\mathrm{Ti} / \mathrm{Au}$ толщиной $50 / 450 \mathrm{~nm}$ соответственно. Рисунок металлизации наноструктурированных плазмонных решеток формировался методом электроннолучевой литографии с аналогичным нанесением металла. Плазмонная решетка, состоящая из слоев $\mathrm{Ti} / \mathrm{Au}$ толщиной 20/80 nm соответственно имеет следующие параметры: период $200 \mathrm{~nm}$, ширина $100 \mathrm{~nm}$. Сверху изготовленные решетки покрывались защитным просветляющим слоем $\mathrm{Al}_{2} \mathrm{O}_{3}$ толщиной $180 \mathrm{~nm}$. Изображение изготовленной ПУ-ФПА представлено на рис. 1, $a$.

Для оценки уменьшения темнового тока за счет формирования диэлектрического слоя были измерены темновые вольт-амперные характеристики (BAX) в диапазоне напряжений от 0 до $10 \mathrm{~V}$. Полученные BAX при- ведены на рис. 1, $b$. Для всех антенн кривые темновых BAX имеют сублинейную зависимость и не выходят на насыщение. Из рис. $1, b$ видно, что наличие диэлектрического слоя на порядок снижает темновой ток, что должно привести к увеличению отношения сигнал/шум (ОСШ). При напряжении $10 \mathrm{~V}$ темновой ток ФПА составляет $\sim 250 \mu \mathrm{A}$, тогда как для Д-ФПА и ПУ-ФПА он равен 18 и $8 \mu \mathrm{A}$ соответственно. Таким образом, ПУ-ФПА демонстрирует самые низкие темновые токи во всем интервале напряжений.

Для анализа взаимодействия оптического излучения накачки с наноструктурированной решеткой в ПУ-ФПА был использован программный пакет на основе метода конечных элементов (COMSOL Multiphysics). Был проведен расчет оптического пропускания сквозь плазмонную решетку до фотопроводящего слоя (рис. 2). Результаты расчета показывают, что выбранная топология плазмонной решетки с просветляющим слоем $\mathrm{Al}_{2} \mathrm{O}_{3}$ толщиной $180 \mathrm{~nm}$ обеспечивает $80 \%$ пропускания оптического излучения накачки в фотопроводящий слой на основе СР-гетероструктуры для длины волны 800 $\mathrm{nm}$. Полученное распределение электрического поля в фотопроводящем слое при лазерной накачке ФПА с длиной волны $800 \mathrm{~nm}$ представлено на вставке к рис. 2.

Исследование параметров детектирования THz-излучения проводилось методом THz-спектроскопии с временны́м разрешением, где в качестве детектора использовались разработанные ФПА. В качества источника

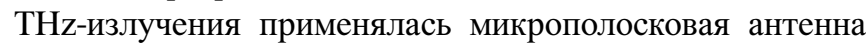
на основе низкотемпературного GaAs (low-temperature grown GaAs — LT-GaAs). Для возбуждения, а также для детектирования THz-излучения использовался лазер Mai Tai-Spectra Physics с рабочей длиной волны $800 \mathrm{~nm}$, длительностью импульсов $100 \mathrm{fs}$ и частотой следования импульсов $82 \mathrm{MHz}$. Исходный лазерный луч с помощью светоделительной пластины разделялся на два луча: луч накачки и луч зондирования. Луч накачки, проходя через

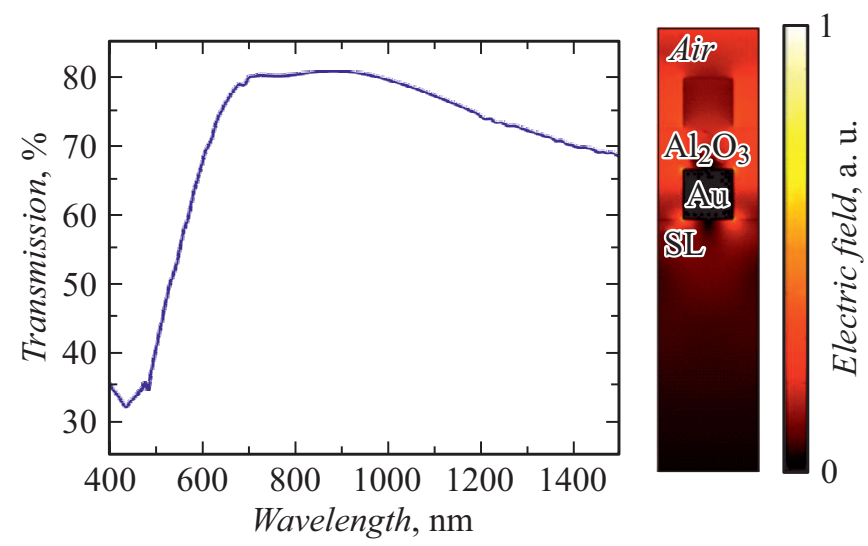

Рис. 2. Спектр пропускания оптического излучения через наноструктурированную решетку (плазмонную решетку) с нанесенным сверху просветляющим покрытием $\mathrm{Al}_{2} \mathrm{O}_{3}$. На вставке - распределение электрического поля в фотопроводящем слое при лазерной накачке ФПА с длиной волны $800 \mathrm{~nm}$. 

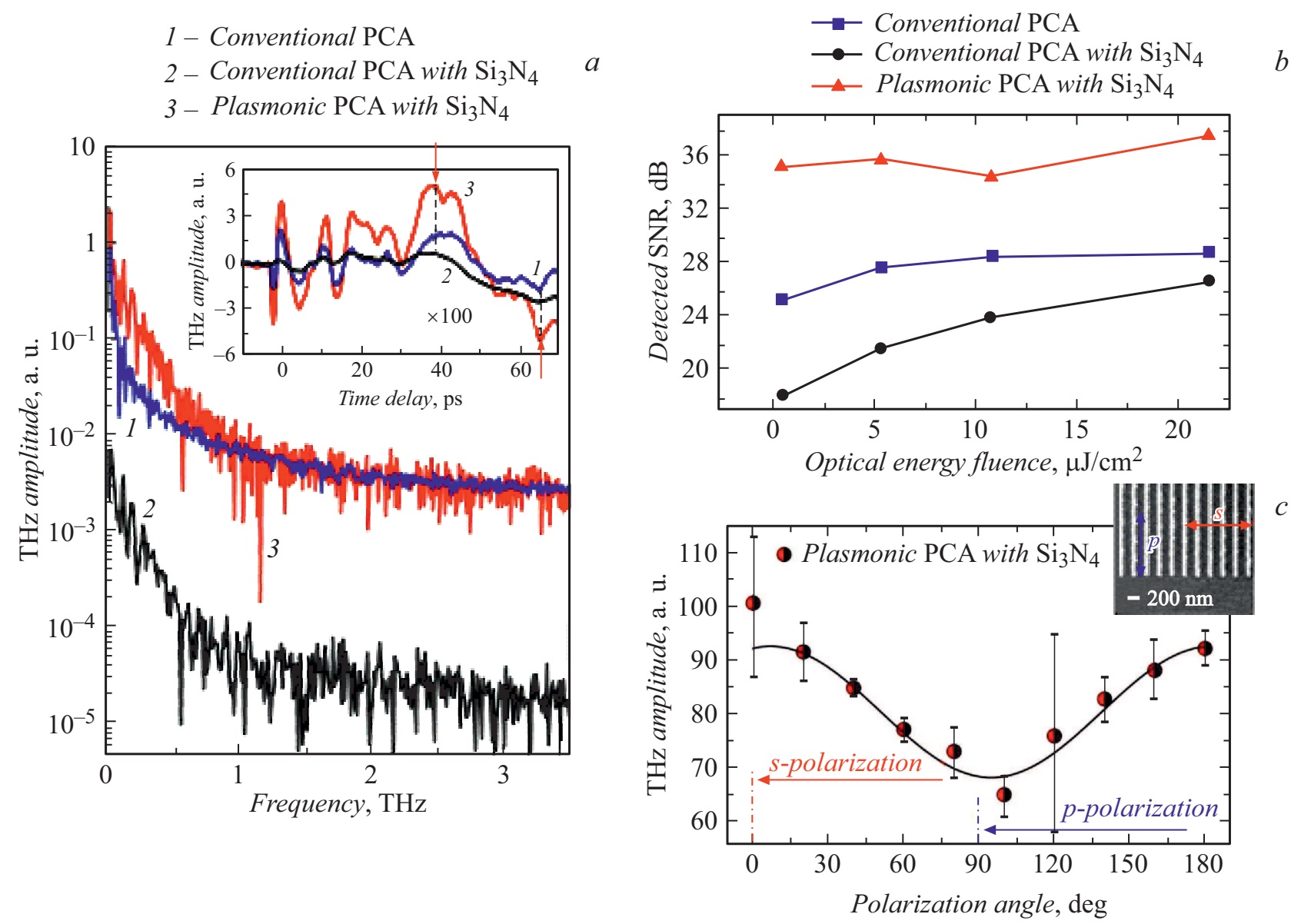

Pис. 3. $a-$ частотные спектры детектируемых антеннами THz-сигналов. На вставке представлены зависимости амплитуды детектируемого антеннами THz-излучения от времени задержки между импульсом накачки и зондирования. $b-$ зависимость детектируемого антеннами ОСШ от плотности энергии лазерного импульса. $c$ - зависимость амплитуды детектируемого ПУ-ФПА THz-сигнала от угла поляризации оптического луча.

линию задержки, фокусировался в зазоре микрополосковой антенны на основе LT-GaAs, к электродам которой прикладывалось постоянное напряжение $30 \mathrm{~V}$. THz-импульс, генерируемый антенной, собирался и фокусировался параболическими зеркалами со стороны подложки. Зондирующий импульс фокусировался в зазоре между электродами детектора. Плотность энергии пучка зондирования составляла $\sim 21.5 \mu \mathrm{J} / \mathrm{cm}^{2}$. Для увеличения чувствительности схемы пучок накачки модулировался оптическим прерывателем на частоте $\sim 400 \mathrm{~Hz}$, а для измерения разности потенциалов, возникающей на электродах детектора, использовался синхронный усилитель SR 830. В случае ФПА и Д-ФПА зондирующий луч был $p$-поляризован (вектор напряженности электрического поля колебался вдоль зазора между электродами). В случае ПУ-ФПА для возбуждения поверхностных плазмонных волн зондирующий луч был $s$-поляризован (вектор напряженности электрического поля колебался в направлении, перпендикулярном периодической металлической решетке). Все измерения проводились при комнатной температуре.
На рис. 3, $a$ представлены временны́е формы и частотные спектры детектируемых THz-сигналов. Частотные спектры были получены методом фурье-преобразования.

По результатам измерений полоса пропускания исследуемых ФПА-детекторов достигала $1.5 \mathrm{THz}$. Максимум амплитуды детектируемого THz-сигнала для всех образцов соответствует частоте $\sim 10 \mathrm{GHz}$. Для обычной ФПА в диапазоне частот до $0.5 \mathrm{THz}$ наблюдается заметный спад амплитуды детектируемого THz-сигнала по сравнению с таковой для антенн с диэлектрическим слоем $\mathrm{Si}_{3} \mathrm{~N}_{4}$. Отметим, что наличие диэлектрического слоя в антеннах Д-ФПА и ПУ-ФПА способствует снижению регистрируемого фототока (по сравнению с обычной ФПА). При этом фототок, регистрируемый Д-ФПА, в $\sim 100$ раз меньше, чем у ФПА (вставка на рис. $3, a$ ). Для ПУ-ФПА наблюдается увеличение регистрируемого фототока в 3 и 300 раз по сравнению с фототоком в случае ФПА и Д-ФПА соответственно. Увеличение регистрируемого фототока для антенны ПУ-ФПА с диэлектрическим слоем по сравнению с аналогичным параметром ФПА связано с увеличением поглощения 
лазерного излучения в фотопроводящем слое за счет плазмонных эффектов и наличия просветляющего покрытия.

На рис. $3, b$ представлены результаты исследования зависимости ОСШ от плотности энергии лазерного импульса. Для этого плотность энергии лазерного излучения менялась в диапазоне $0.5-21.5 \mu \mathrm{J} / \mathrm{cm}^{2}$. Наибольшее увеличение ОСШ в исследуемом диапазоне плотности лазерной энергии наблюдалось для ФПА и составило $8 \mathrm{~dB}$. Для Д-ФПА и ПУ-ФПА наблюдалось лишь незначительное увеличение ОСШ на $2-3 \mathrm{~dB}$. Для ФПА максимальное значение ОСШ при плотности лазерной энергии $21.5 \mu \mathrm{J} / \mathrm{cm}^{2}$ составило $28.7 \pm 0.3 \mathrm{~dB}$, для ДФПА $-26.6 \pm 0.5 \mathrm{~dB}$, для ПУ-ФПА $-37.5 \pm 0.5 \mathrm{~dB}$. В измерениях ОСШ определялось путем усреднения по четырем экспериментальным точкам. Увеличение ОСШ в основном связано с уменьшением шумового (темнового) тока и зависит от количества экспериментальных точек [19]. Поэтому полученное значение ОСШ может быть значительно увеличено, если измерения не ограничены во времени.

Поскольку поверхностные плазмоны в ФПА возбуждаются при ТМ-поляризации падающего оптического возбуждения [4,17], ПУ-ФПА ожидаемо имеет чувствительность к поляризации волны лазерной накачки. Известно, что наноразмерная периодическая металлическая решетка способна увеличивать пропускание оптического излучения в подложку за счет возбуждения канализированных плазмонных мод, распространяющихся в щелевых волноводах между электродами металлической структуры [20]. При этом максимальное пропускание оптического излучения будет достигаться только в том случае, если вектор напряженности электрического поля в волне колеблется перпендикулярно решеточной структуре; в противном случае эффективность пропускания такой решетки значительно хуже. Чувствительность ПУ-ФПА к повороту вектора поляризации оптического излучения была верифицирована экспериментально. Мощность зондирующего луча составляла $100 \mathrm{~mW}$ (плотность энергии $11 \mu \mathrm{J} / \mathrm{cm}^{2}$ ). На рис. 3, $c$ представлена

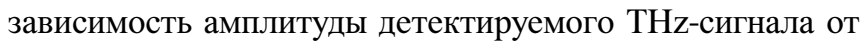
угла поворота плоскости поляризации зондирующего луча. Как и предполагалось, максимальная амплитуда THz-сигнала наблюдается для ТМ-поляризованной световой волны, при которой вектор напряженности электрического поля ориентирован перпендикулярно плазмонным электродам решетки ( $s$-поляризация). При дальнейшем повороте угла поляризации вплоть до $\sim 90^{\circ}$ ( $p$-поляризация) чувствительность ПУ-ФПА снижается на $25 \%$.

Таким образом, в работе предложен эффективный THz-детектор на основе ФПА, в которой края электродов структурированы специальным образом для увеличения чувствительности детектора. Дополнительно мы использовали диэлектрический слой $\mathrm{Si}_{3} \mathrm{~N}_{4}$ для уменьшения токов утечки ФПА и соответственно уровня шума в антенне-детекторе. Показано резкое снижение темнового тока по сравнению с таковым для коммерческих антенн на основе InGaAs [5]. В ходе исследования изготовленных ФПА методом THz-спектроскопии с временны́м разрешением установлено, что максимальный фототок, регистрируемый ПУ-ФПА, в 3 раза выше, чем у ФПА, и в 300 раз выше, чем у Д-ФПА. Полоса пропускания всех антенн составляет $1.5 \mathrm{THz}$. Показано, что ПУ-ФПА имеет самое высокое значение ОСШ ( $\sim 38.5 \mathrm{~dB})$. Эффективность взаимодействия оптического излучения с наноструктурированной металлической решеткой была экспериментально подтверждена путем измерения зависимости амплитуды THz-сигнала от угла поляризации оптического луча.

\section{Финансирование работы}

Исследование выполнено при финансовой поддержке Министерства образования и науки РФ (государственное задание № FSFZ-0706-2020-0022) (в части экспериментальных исследований временны́х и спектральных характеристик THz-излучения) и Российского фонда фундаментальных исследований (проект № 20-32-70129) (в части изготовления и общей характеризации образцов).

\section{Конфликт интересов}

Авторы заявляют, что у них нет конфликта интересов.

\section{Список литературы}

[1] Globisch B., Dietz R.J.B., Kohlhaas R.B., Göbel T., Schell M., Alcer D., Semtsiv M., Masselink W.T. // J. Appl. Phys. 2017. V. 121. N 5. P. 053102.

[2] Буряков А.М., Хусяинов Д.И., Мишина Е.Д., Хабибуллин Р.А., Ячменев А.Э., Пономарев Д.С. // Письма в ЖТФ. 2018. T. 44. B. 23. C. $146-157$.

[3] Хусяинов Д.., Буряков А.М., Билык В.Р., Мишина Е.Д., Пономарев Д.С., Хабибуллин Р.А., Ячменев А.Э. // Письма в ЖТФ. 2017. Т. 43. В. 22. С. $48-54$.

[4] Yardimci N.T., Jarrahi M. // Sci. Rep. 2017. V. 7. N 1. P. 42667.

[5] https://www.batop.de/products/terahertz/photoconductive-antenna/photoconductive-antenna-1550nm.html

[6] Takazato A., Kamakura M., Matsui T., Kitagawa J., Kadoya Y. // Appl. Phys. Lett. 2007. V. 90. N 10. P. 101119.

[7] Takazato A., Kamakura M., Matsui T., Kitagawa J., Kadoya Y. // Appl. Phys. Lett. 2007. V. 91. N 1. P. 011102.

[8] Carmody C., Tan H.H., Jagadish C., Gaarder A., Marcinkevičus S. // Appl. Phys. Lett. 2003. V. 82. N 22. P. 3913-3915.

[9] Suzuki M., Tonouchi M. // Appl. Phys. Lett. 2005. V. 86. N 5. P. 051104 (1-3).

[10] Wood C.D., Hatem O., Cunningham J.E., Linfield E.H., Davies A.G., Cannard P.J., Robertson M.J., Moodie D.G. // Appl. Phys. Lett. 2010. V. 96. N 19. P. 194104.

[11] Chimot N., Mangeney J., Joulaud L., Crozat P., Bernas H., Blary K., Lampin J.F. // Appl. Phys. Lett. 2005. V. 87. N 19. P. $193510(1-3)$. 
[12] Driscoll D.C., Hanson M.P., Gossard A.C., Brown E.R. // Appl. Phys. Lett. 2005. V. 86. N 5. P. 051908 (1-3).

[13] Dietz R.J.B., Globisch B., Roehle H., Stanze D., Göbel T., Schell M. // Opt. Express. 2014. V. 22. N 16. P. 19411.

[14] Dietz R.J.B., Globisch B., Gerhard M., Velauthapillai A., Stanze D., Roehle H., Koch M., Göbel T., Schell M. // Appl. Phys. Lett. 2013. V. 103. N 6. P. 061103.

[15] Ponomarev D.S., Gorodetsky A., Yachmenev A.E., Pushkarev S.S., Khabibullin R.A., Grekhov M.M., Zaytsev K.I., Khusyainov D.I., Buryakov A.M., Mishina E.D. // J. Appl. Phys. 2019. V. 125. N 15. P. 151605.

[16] Lepeshov S., Gorodetsky A., Krasnok A., Rafailov E., Belov P. // Laser Photon. Rev. 2017. V. 11. N 1. P. 1600199.

[17] Lavrukhin D.V., Yachmenev A.E., Glinskiy I.A., Khabibullin R.A., Goncharov Y.G., Ryzhii M., Otsuji T., Spector I.E., Shur M., Skorobogatiy M., Zaytsev K.I., Ponomarev D.S. // AIP Adv. 2019. V. 9. N 1. P. 015112.

[18] Лаврухин Д.В., Ячменев А.Э., Глинский И.А., Зенченко Н.В., Хабибуллин Р.А., Гончаров Ю.Г., Спектор И.Е., Зайцев К.И., Пономарев Д.С. // Оптика и спектроскопия. 2020. T. 129. В. 7. С. $1012-1019$.

[19] Vieweg N., Rettich F., Deninger A., Roehle H., Dietz R., Göbel T., Schell M. // J. Infrared Millimeter Terahertz Waves. 2014. V. 35. N 10. P. 823-832.

[20] Лаврухин Д.В., Галиев Р.Р., Павлов А.Ю., Ячменев А.Э., Майтама М.В., Глинский И.А., Хабибуллин Р.А., Гончаров Ю.Г., Зайцев К.И., Пономарев Д.С. // Оптика и спектроскопия. 2019. Т. 126. В. 5. С. 663-669. 